\title{
EXCESSIVE FERTILIZATION RESULTED IN DECREASED ANTIOXIDANT PERFORMANCE OF THREE VARIETIES OF SUPER RICE
}

\author{
ZHANG, T. T. ${ }^{1,2 \#}-$ LI, Y. Z. ${ }^{1,2 \#}-$ XIE, W. J. ${ }^{1,2 \#}-$ DU, P. ${ }^{3}-$ LU, R. H. ${ }^{1}-$ CHEN, Y. L. ${ }^{1}-$ LAI, R. F. ${ }^{1}-$ \\ ZHENG, A. X. ${ }^{1}-$ TANG, X. R. ${ }^{1,2^{*}}$ \\ ${ }^{I}$ Department of Crop Science and Technology, College of Agriculture, South China Agricultural \\ University, Guangzhou 510642, PR China \\ ${ }^{2}$ Scientific Observing and Experimental Station of Crop Cultivation in South China, Ministry of \\ Agriculture, Guangzhou 510642, PR China \\ ${ }^{3}$ Key Laboratory of Key Technology for South Agricultural Machine and Equipment, Ministry of \\ Education, Guangzhou 510642, PR China \\ ${ }^{\#}$ These authors have contributed equally to this work \\ *Corresponding author \\ e-mail: tangxr@scau.edu.cn \\ (Received 28 ${ }^{\text {th }}$ Oct 2018; accepted $11^{\text {th }}$ Jan 2019)
}

\begin{abstract}
Fertilizer application is an important part in super rice production. In order to investigate the effect of fertilizer amounts on the antioxidant performance of the super rice, three super hybrid rice cultivars, YLiangyou-1173, YLiangyou-911 and Chaoyou-1000, were used in the experiment. The fertilizer amounts were set as: (F1)1050 $\mathrm{kg} \mathrm{N}^{-1}$; (F2) $1200 \mathrm{~kg} \mathrm{~N}^{-1}$; (F3) $1350 \mathrm{~kg} \mathrm{~N} \mathrm{ha}^{-1}$; (F4) $1500 \mathrm{~kg} \mathrm{~N}^{-1}$; (F5) $1650 \mathrm{~kg} \mathrm{~N}^{-1}$. The results showed that the activities of antioxidant enzymes were decreased when excessive fertilizers such as F4 and F5 were applied. Compared with F1, F4 and F5 significantly reduced the activity of superoxide (SOD, EC 1.15.1.1), guaiacol type peroxidase (POD EC1.11.1.7) and catalase (CAT, EC1.11.1.6). Furthermore, there was no remarkable significant difference related to the yield among F2, F3, F4 and F5.
\end{abstract}

Keywords: rice, superoxide, catalase, peroxidase, yield, fertilizer

\section{Introduction}

Rice (Oryza sativa L.) has been cultivated in China for a very long time and its production has played an important role in Chinese food security (Ren et al., 2017). Many experts had done many researches in different fields to improve to improve rice yield and quality (Wang and Zhang, 2017; Wu et al., 2018; Jiang et al., 2018). Generating rice varieties with high yield potential is a main method to improve rice yield. In 1996, China's ministry of agriculture proposed the super hybrid rice cultivation program which was led by Yuan Longping, the "father of hybrid rice", in 2000, the super hybrid rice varieties reached the first-stage single rice yield standard, that is, the yield per hectare exceeded 10.5 tons and in 2004, the output of super hybrid rice reached the second stage (Schmalzer, 2017). Normally, in order to improve the potential of yield and increase the final yield of super rice, researchers and farmers would apply as much fertilizer as possible and try to found the correlation between rice yield and fertilizing amount. However, there was no much report about the effect of fertilizer amount on rice physiological property especially antioxidant property.

The antioxidant system is very important when rice faces the environment stress such as heat stress, chilling, heavy metal stress and it also has relationship with rice yield and 
quality. When rice faces the environmental stress including UV stress and pathogen invasion, the reactive oxygen species (ROS) will be produced and accumulated while oxidative stress is induced. Then, a lot of cellular reactions will be produced in by various enzymes such as superoxide dismutase (SOD), catalase (CAT) and peroxidase (POD). The formation of ROS is prevented and decreased by an antioxidant system which including ROS-interacting enzymes such as SOD, CAT and POD (Blokhina, 2003). The study of Kong (Kong et al., 2017) showed that the malondialdehyde (MDA) content would increase when rice suffered from high temperature stress at filling stage and the soluble protein, POD, SOD, CAT and free proline would work together to quench the ROS and decrease the MDA concentration. Pan (Pan et al., 2013) demonstrated that spraying paclobutrazol (PBZ) and 6-Benzylaminopurine (6-BA) at heading stage could not only increase POD and SOD activities but also improve the rice yield and grain quality.

Many researches had proved that fertilizer application is a key part in rice production (Shakoor et al., 2018; Liu et al., 2018). The study of Li et al. (2016) showed that manganese $(\mathrm{Mn})$ fertilizer could enhance enzyme activity involved in 2-acetyl-1-pyrroline (2-AP) biosynthesis in fragrant rice while regulating the grain yield. The investigation of Pan et al. (2017) revealed that mechanized deep placement of nitrogen fertilizer in direct-seeded rice improved rice yield by promoting the fertilizer uptake of rice and increasing the utilization rate. Fertilizer application is the other source of rice nutrition beside photosynthesis and it also could affect the rice growth environment such as soil properties (Sun et al., 2018; Ghaley et al., 2018). However, the relationship between fertilizer amount and rice antioxidant property is still unknown to us.

Therefore, the study was conducted in Guangzhou, Guangdong (major rice producing province in South China) in early season in 2018 in order to investigate the effect of different amount of fertilizer on antioxidant performance of three super rice cultivars.

\section{Materials and methods}

\section{Plant materials and growing condition}

Three super hybrid rice cultivars, YLiangyou-1173, YLiangyou-911 and Chaoyou-1000, well-known and widely grown in South China, were in planted in the early season in Guangzhou ( $23^{\circ} 16^{\prime} \mathrm{N}, 113^{\circ} 23^{\prime}$ E) during 2018. Before sowing, the seeds were soaked in water for $24 \mathrm{~h}$, germinated in manual climatic box for the next $24 \mathrm{~h}$, shade dried and the germinated seeds were sown in PVC trays for nursery raising. 20-day-old seedlings were transplanted to the field at the planting distance $(30 \mathrm{~cm} \times 12 \mathrm{~cm})$. The experimental soil in Guangzhou was sandy loam with of $24.65 \%$ organic matter content, $1.560 \%$ total N, $0.956 \%$ total $\mathrm{P}$, and $18.460 \%$ total $\mathrm{K}$.

\section{Treatments and plant sampling}

Five amounts of commercial compound fertilizer were applied at the experiment and set as below:

F1: $1050 \mathrm{~kg} \mathrm{ha}^{-1}$ commercial compound fertilizer (pure nitrogen $131.25 \mathrm{~kg} \mathrm{ha}^{-1}$, pure phosphate $63 \mathrm{~kg} \mathrm{ha}^{-1}$, pure potassium $105 \mathrm{~kg} \mathrm{ha}^{-1}$, organic fertilizer $210 \mathrm{~kg} \mathrm{ha}^{-1}$ );

F2: $1200 \mathrm{~kg} \mathrm{ha}^{-1}$ commercial compound fertilizer (pure nitrogen $150 \mathrm{~kg} \mathrm{ha}^{-1}$, pure phosphate $72 \mathrm{~kg} \mathrm{ha}^{-1}$, pure potassium $120 \mathrm{~kg} \mathrm{ha}^{-1}$, organic fertilizer $240 \mathrm{~kg} \mathrm{ha}^{-1}$ );

F3: $1350 \mathrm{~kg} \mathrm{ha}^{-1}$ commercial compound fertilizer (pure nitrogen $168.75 \mathrm{~kg} \mathrm{ha}^{-1}$, pure phosphate $81 \mathrm{~kg} \mathrm{ha}^{-1}$, pure potassium $135 \mathrm{~kg} \mathrm{ha}^{-1}$, organic fertilizer $270 \mathrm{~kg} \mathrm{ha}^{-1}$ ); 
F4: $1500 \mathrm{~kg} \mathrm{ha}^{-1}$ commercial compound fertilizer (pure nitrogen $187.50 \mathrm{~kg} \mathrm{ha}^{-1}$, pure phosphate $90 \mathrm{~kg} \mathrm{ha}^{-1}$, pure potassium $150 \mathrm{~kg} \mathrm{ha}^{-1}$, organic fertilizer $300 \mathrm{~kg} \mathrm{ha}^{-1}$ );

F5: $1650 \mathrm{~kg} \mathrm{ha}^{-1}$ commercial compound fertilizer (pure nitrogen $206.25 \mathrm{~kg} \mathrm{ha}^{-1}$, pure phosphate $99 \mathrm{~kg} \mathrm{ha}^{-1}$, pure potassium $165 \mathrm{~kg} \mathrm{ha}^{-1}$, organic fertilizer $330 \mathrm{~kg} \mathrm{ha}^{-1}$ ).

The fertilizer was invented by Tang Xiangru (CN 101955394 A). The special fertilizer is a mixture of nitrogen $(\mathrm{N})$ fertilizer, phosphate $(\mathrm{P})$ fertilizer, potassium $(\mathrm{K})$ fertilizer and biological organic fertilizer $(12.50 \% \mathrm{~N}, 6.00 \% \mathrm{P}, 10.00 \% \mathrm{~K}$ and $20.00 \%$ organic matter content). Normally, the local farmers in Guangdong were used to applied $1500 \mathrm{~kg} \mathrm{ha}^{-1}$. The treatments were arranged in randomized complete block design (RCBD) in triplicate in each year with net plot size of $20 \mathrm{~m}^{2}$.

The fresh flag leaves were separated and collected from the rice plants at tillering stage, heading stage and maturity stage, respectively. The sample was washed with double distilled water and stored at $-80^{\circ} \mathrm{C}$ for physio-biochemical analysis.

\section{Measurement of malondialdehyde (MDA) and anti-oxidants responses}

The MDA content and activities of POD, SOD and CAT were determined according to the methods described by Kong et al. (2017). MDA reacted with thiobarbituric acid (TBA) and the absorbance was read at the $532 \mathrm{~nm}, 600 \mathrm{~nm}$, and $450 \mathrm{~nm}$. The content of the reaction solution was calculated as: MDA content $(\mu \mathrm{mol} / \mathrm{L})=6.45(\mathrm{OD} 532-\mathrm{OD} 600)-$ $0.56 \mathrm{OD} 450$, while the final result was expressed as $\mu \mathrm{mol} / \mathrm{g} \mathrm{FW}$.

Guaiacol type peroxidase (POD EC1.11.1.7) activity was estimated after the reaction which the solution was including enzyme extract $(50 \mu \mathrm{l}), 1 \mathrm{ml}$ of $0.3 \% \mathrm{H} 2 \mathrm{O} 2,0.95 \mathrm{ml}$ of $0.2 \%$ guaiacol, and $1 \mathrm{ml}$ of $50 \mathrm{mM} \mathrm{1-1}$ sodium phosphate buffer $(\mathrm{pH} 7.0)$ while One POD unit of enzyme activity was expressed as the absorbance increase because of guaiacol oxidation by 0.01 (U/g FW). The superoxide (SOD, EC 1.15.1.1) activity was measured by using nitro blue tetrazolium (NBT). $0.05 \mathrm{ml}$ of enzyme extract was added into the reaction mixture which contained $1.75 \mathrm{ml}$ of sodium phosphatebuffer (pH 7.8), $0.3 \mathrm{ml}$ of $130 \mathrm{mM}$ methionine buffer, $0.3 \mathrm{ml}$ of $750 \mu \mathrm{mol} \mathrm{L}{ }^{-1}$ NBT buffer, $0.3 \mathrm{ml}$ of $100 \mu \mathrm{mol} \mathrm{L}{ }^{-1}$ EDTA-Na 2 buffer and $0.3 \mathrm{ml}$ of $20 \mu \mathrm{mol} \mathrm{L}-1$ lactoflavin. After reaction, the absorbance was recorded at $560 \mathrm{~nm}$. One unit of SOD activity is equal to the volume of extract needed to cause $50 \%$ inhibition of the color reaction. Catalase (CAT, EC1.11.1.6) activity was estimated by adding an aliquot of enzyme extract (50 $\mu \mathrm{l}$ ) to the reaction solution containing $1 \mathrm{ml}$ of $0.3 \%$ $\mathrm{H} 2 \mathrm{O} 2$ and $1.95 \mathrm{ml}$ of sodium phosphate buffer and then the absorbance was read at 240 $\mathrm{nm}$. One CAT unit of enzyme activity was defined as the absorbance decrease by 0.01 (U/g FW).

\section{Estimation of rice yield}

At maturity stage, the rice grains were harvested from ten unit sampling area $\left(1.00 \mathrm{~m}^{2}\right)$ in each plot and then threshed by machine. The harvested grains were sundried and weighed in order to determinate the grain yield.

\section{Statistical analysis}

Data were analyzed using statistical software 'Statistix 8.1'(Analytical Software, Tallahassee, FL, USA) while differences amongst means were separated by using least significant difference (LSD) test at 5\% probability level. Graphical representation was conducted via Sigma Plot 14.0 (Systat Software Inc., California, USA). 


\section{Results}

\section{SOD activity}

As shown in Figure 1, there were some differences on SOD activity among different fertilizer amounts. For YLiangyou-1173, there was no remarkable difference between F1 and F2. However, F4 and F5 had lower SOD activity than F1 at tillering stage, heading stage and maturity stage. The trend of SOD activity at tillering stage and maturity stage was recorded as: F1 = F2 > F3 > F4 > F5. For YLiangyou-911, the activity decreased with the increase of fertilizer amount. The lowest activity was recorded in F5 while the highest was recorded in F1 at tillering stage and heading stage. The trend at maturity was recorded as: $\mathrm{F} 1>\mathrm{F} 2=\mathrm{F} 3>\mathrm{F} 4=\mathrm{F} 5$. For Chaoyou-1000, at tillering stage, the trend of SOD activity was recorded as: $\mathrm{F} 1=\mathrm{F} 2>\mathrm{F} 3>\mathrm{F} 4=\mathrm{F} 5$, at heading stage, highest activity was recorded in F1 and the lowest was observed in F5 while in maturity stage, there was no significant difference among F1, F2 and F3 while F4 and F5 were significantly lower than F1.
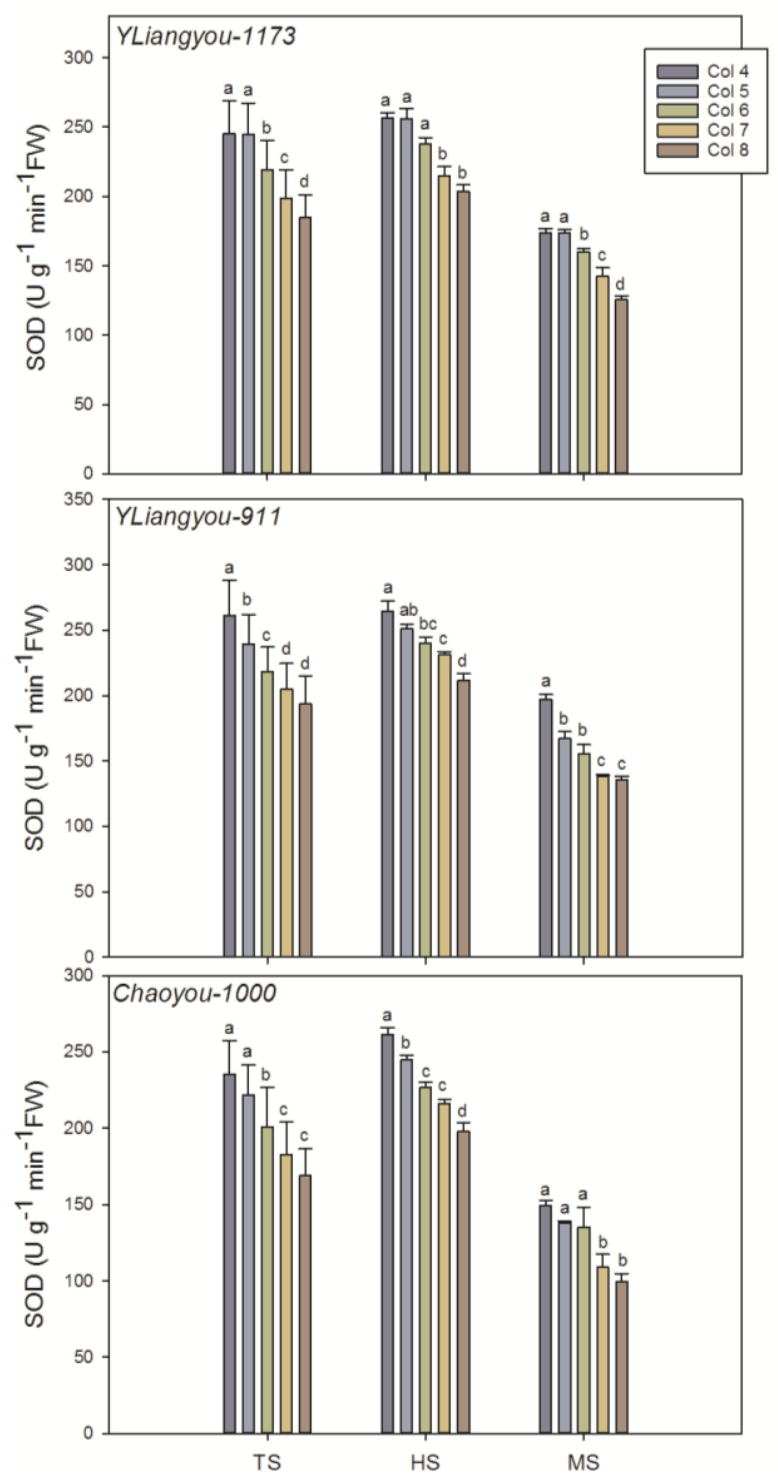

Figure 1. Effect of fertilizer amounts on SOD activity. TS: tillering stage; HS: heading stage; MS: maturity stage. Means sharing a common letter do not differ significantly (at $P<0.05$ ) according to least significant difference (LSD) test for both the seasons 


\section{CAT activity}

As shown in Figure 2, fertilizer amounts affected CAT activity significantly. For YLiangyou-1173, the trends of CAT activity at tillering stage, heading stage and maturity stage were recorded as: $\mathrm{F} 1=\mathrm{F} 2>\mathrm{F} 3>\mathrm{F} 4=\mathrm{F} 5, \mathrm{~F} 1=\mathrm{F} 2 \geq \mathrm{F} 3 \geq \mathrm{F} 4=\mathrm{F} 5, \mathrm{~F} 1=$ $\mathrm{F} 2=\mathrm{F} 3 \geq \mathrm{F} 4 \geq \mathrm{F} 5$, respectively. For YLiangyou-911, at tillering stage, the highest CAT activity was recorded in F1 and there was no remarkable difference among F3, F4 and F5. At heading stage, there was no significant difference among F1, F2, F3 and F4 while F5 had lower activity than F1. At maturity stage, compared with F1, F2, F3, F4 and F5 all significantly reduced the CAT activity while there was no remarkable difference among F2, F3, F4 and F5. For Chaoyou-1000, F3, F4 and F5 all had lower activity than F1 at tillering stage and heading stage, however, at maturity, there was no significant difference among all fertilizer treatments.
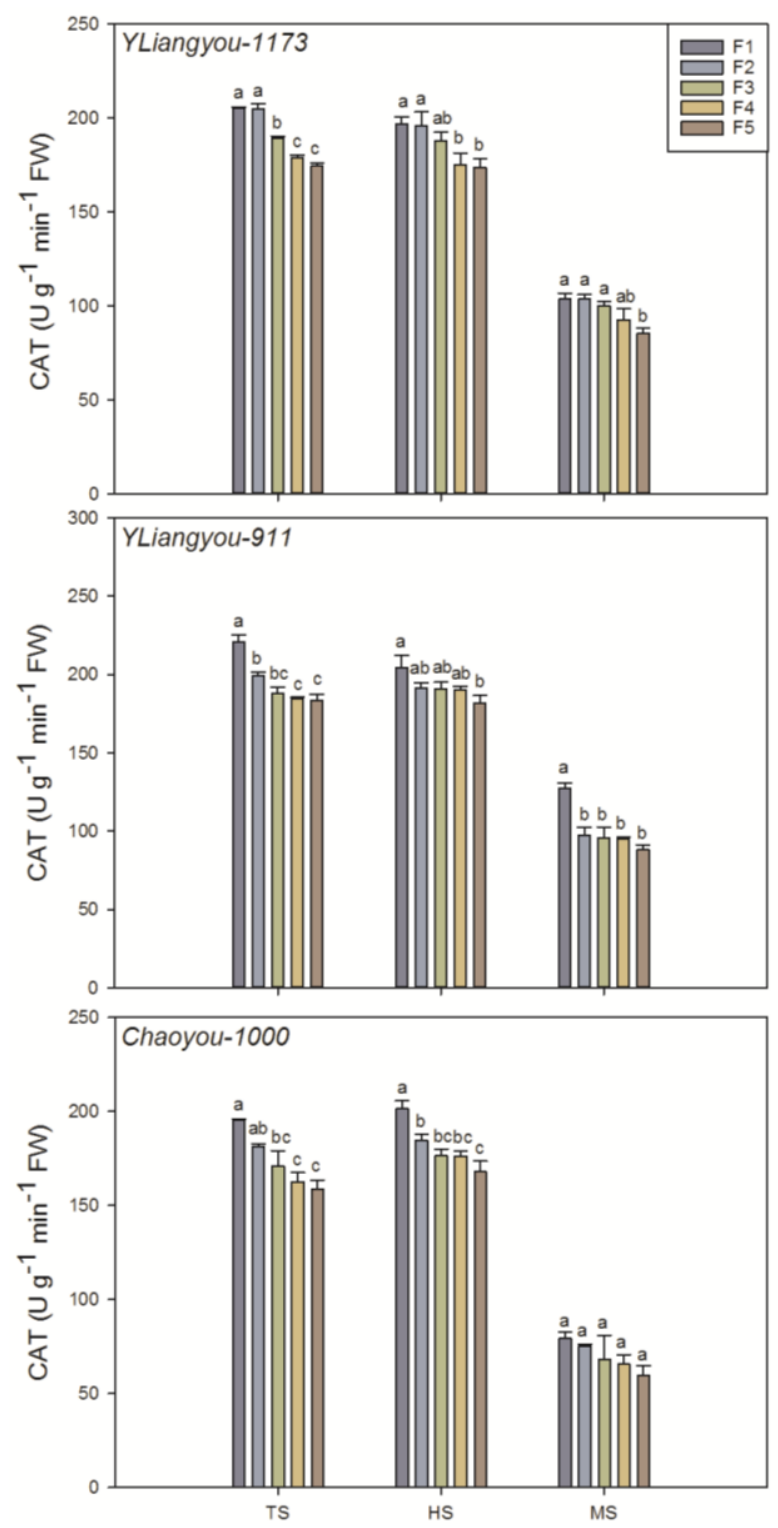

Figure 2. Effect of fertilizer amounts on CAT activity. TS: tillering stage; HS: heading stage; MS: maturity stage. Means sharing a common letter do not differ significantly (at $P<0.05$ ) according to least significant difference (LSD) test for both the seasons 


\section{POD activity}

As shown in Figure 3, fertilizer amounts affected POD activity significantly. For YLiangyou-1173, compared with F1, F4 and F5 reduced the POD activity significantly and there was no significant difference between F2 and F1 at heading stage and maturity stage. For YLiangyou-911, there was no remarkable difference between F1 and F2 at all three growth stage. However, F3, F4, F5 had lower activity than F1 at all three growth stage. For Chaoyou-1000, compared with F1, F4 and F5 significantly decreased the CAT activity at all growth stage. Furthermore, there was no remarkable difference among F1, F2 and F3 at maturity stage.
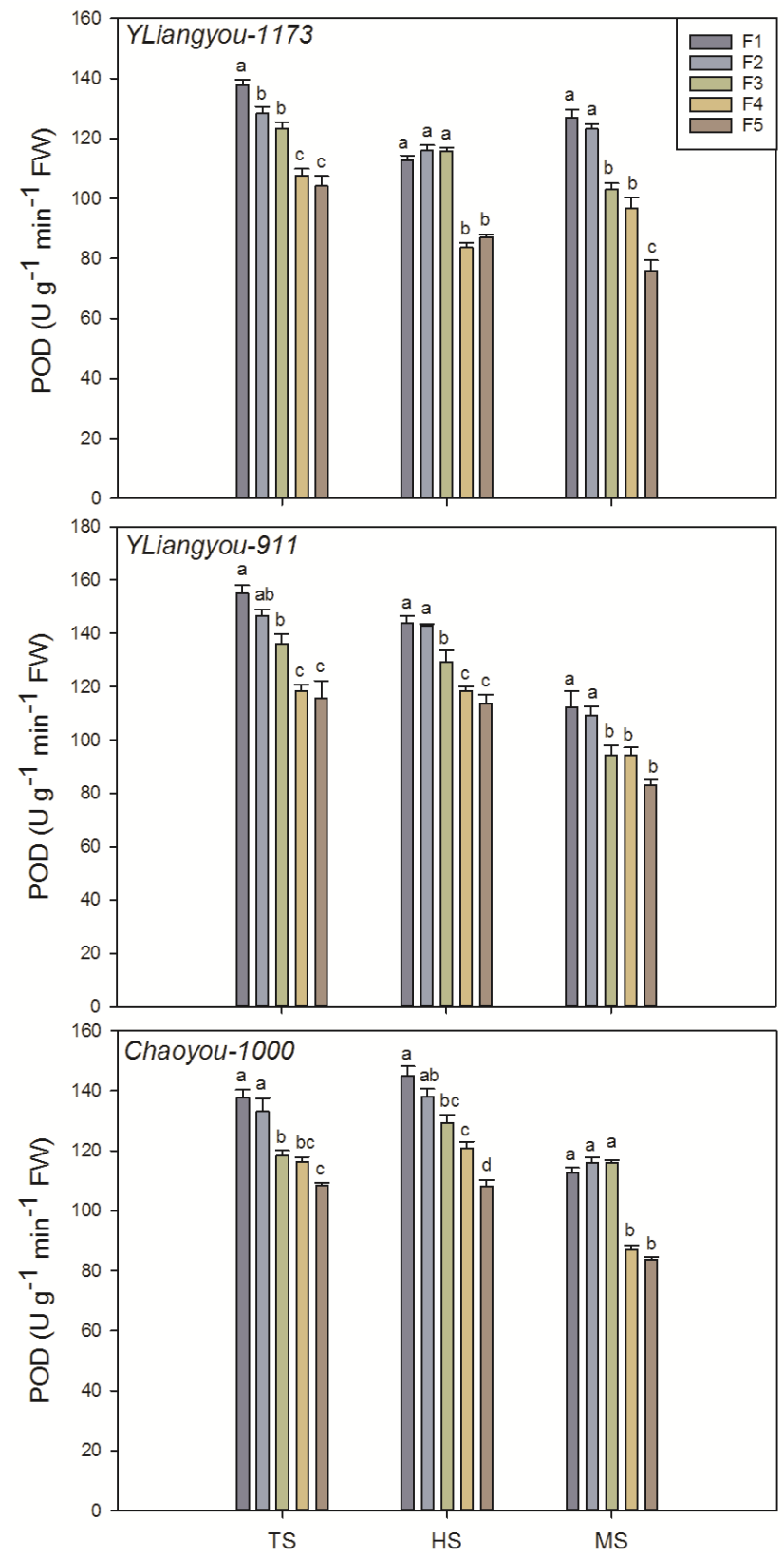

Figure 3. Effect of fertilizer amounts on POD activity. TS: tillering stage; HS: heading stage; MS: maturity stage. Means sharing a common letter do not differ significantly (at $P<0.05$ ) according to least significant difference (LSD) test for both the seasons 


\section{MDA content}

As shown in Figure 4, fertilizer amounts affected MDA concentration significantly. For YLiangyou-1173, the highest MDA content was recorded in F5 and the lowest was recorded in F2. For YLiangyou-911, at tillering stage, there was no significant difference among F1, F2, F3 and F4, at heading stage, the highest content was recorded in F5 while there was no remarkable difference among F1, F2 and F3, at maturity stage, there was no significant difference among all fertilizer treatments. For Chaoyou-1000, the trend of MDA content was recorded as: F5 $>$ F1 $>$ F4 $>$ F3 $>$ F2 at tillering stage, at heading stage, the highest content was recorded in F5 while the lowest was recorded in F2 and F3. At maturity, the highest concentration was recorded in both F5 and F4 while the lowest was recorded in F1.

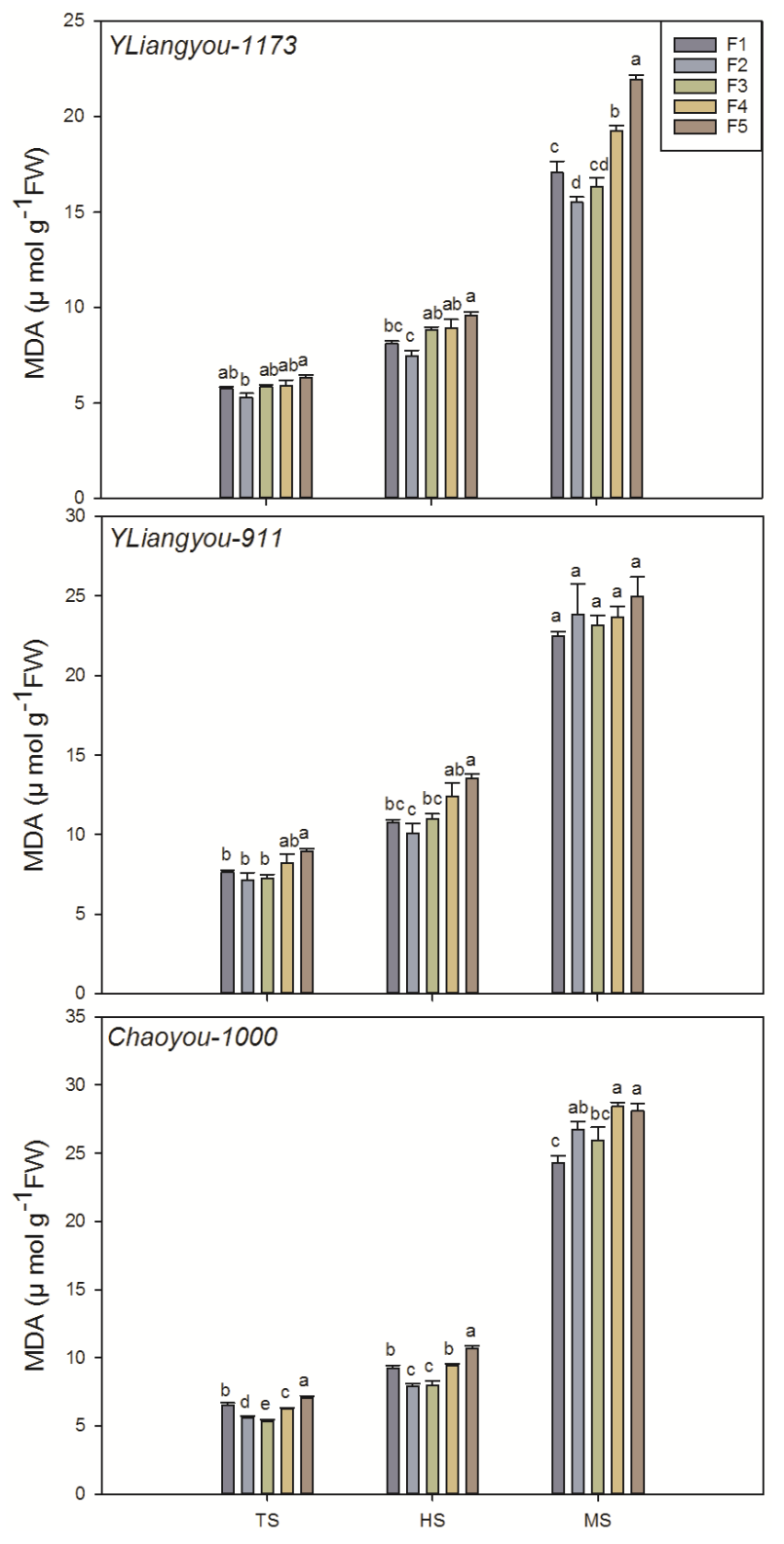

Figure 4. Effect of fertilizer amounts on MDA content. TS: tillering stage; HS: heading stage; MS: maturity stage. Means sharing a common letter do not differ significantly (at $P<0.05$ ) according to least significant difference (LSD) test for both the seasons 


\section{Yield}

As shown in Figure 5, fertilizer amounts affected grain yield significantly. For YLiangyou-1173, F2, F3, F4 and F5 had higher yield than F1 but there was no remarkable difference among F2, F3, F4 and F5. For YLiangyou-911, with the increase of fertilizer application, the yield increased first and then decreased but there was no significant difference between two adjacent fertilizer gradients. For Chaoyou-1000, the trend of was recorded as: $\mathrm{F} 5=\mathrm{F} 4=\mathrm{F} 3 \geq \mathrm{F} 2 \geq \mathrm{F} 1$.

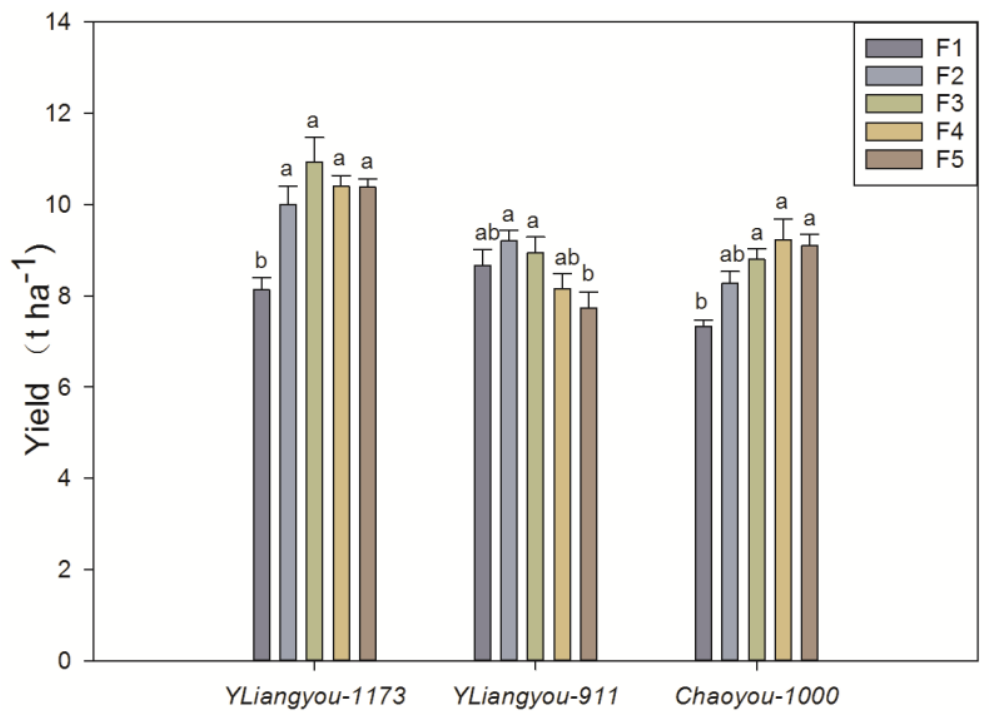

Figure 5. Effect of fertilizer amounts on yield. Means sharing a common letter do not differ significantly (at $P<0.05)$ according to least significant difference $(L S D)$ test for both the seasons

\section{Discussion}

The effect of fertilizer on rice had been reported by many researchers. Mo et al. (2017) demonstrated that Silicon ( $\mathrm{Si}$ ) fertilizer had ability to regulate the fragrant rice yield and the content of 2-AP. The research of Sikar et al. (2008) showed that $80 \mathrm{~kg} \mathrm{hm}^{-}$ 2 nitrogen improved grain quality significantly and the nitrogen utilization efficiency is connected to the locations and rice genotypes. Previous study (Mahajan et al., 2010) also revealed that high nitrogen application could cause the lodging in rice. In our study, we observed that different amounts of fertilizer influenced the super rice antioxidant system in terms of POD, SOD, CAT and MDA. The result showed that F4 and F5 treatments reduced the enzymes activity significantly which indicated excessive fertilization might improve rice growth, but would reduce the antioxidant capacity.

Antioxidant capacity which involves antioxidant enzymes such as POD, SOD and CAT is a key indicator to measure the ability of rice to resist environmental stress (Almeselmani et al., 2006). Normally, when rice faces environmental stress such as heat damage, chilling, heavy metal stress or extreme weather, the reactive oxygen species (ROS) concentration would increase quickly and cause a number of reactions (ZhangWei and Peng, 2018). For example, the peroxidation of unsaturated fatty acid in plant membranes induced by ROS, resulting in a decrease in the content of unsaturated fatty acid, an increase in MDA concentration and a decreased in membrane fluidity (ElShintinawy, 2000), then, POD, SOD and CAT would play an important part in 
quenching the ROS and lowering the MDA content. In our study, the results showed that the activity of antioxidant enzymes including SOD, CAT and POD would decrease if too much fertilizer was applied in super rice production. The decrease in antioxidant enzymes activity meant that the reduction of rice ability to quench the ROS and decreased MDA. Then, the risk of environmental stress and disease would be increased.

The harm of excessive fertilization had been reported in previous studies. For example, the study of Zhong and $\mathrm{Zu}$ (1997) revealed that supplying with excessive phosphate $(\mathrm{P})$ fertilizer in early stage could not increase yield more than that applied with adequate $\mathrm{P}$, due to the reduction in the valid grain percentage and weight per thousand grains. Similar phenomenon also was found in present study by showing that both F4 and F5 did not have a higher yield than F3. The investigation of Peng et al. (2010) showed that excessive nitrogen application to rice in China could cause environmental pollution, increase the cost of rice farming, reduce grain yield and contribute to global warming. From the perspective of antioxidant performance of rice, this experiment proved again that the importance of moderate fertilization and the harm of excessive fertilization.

\section{Conclusion}

Excessive fertilization could cause the decrement of activity of antioxidant enzymes such as SOD, POD and CAT, thus reduced antioxidant capacity of super rice. In rice production, people should pay more attention on rational application of fertilizer and for revealing the mechanism of how fertilizer amounts affecting rice antioxidant system, much work should be done at molecular and physiological level.

Acknowledgements. This study was supported by National Natural Science Foundation of China (31271646), National Key R\&D Program of China (2016YFD0700301), the World Bank Loan Agricultural Pollution Control Project in Guangdong (0724-1510A08N3684), the Technology System of Modern Agricultural Industry in Guangdong (2017LM1098) and Student's Platform for Innovation and Entrepreneurship Training Program (201810564029). The authors declare no conflict of interests.

\section{REFERENCES}

[1] Almeselmani, M., Deshmukh, P. S., Sairam, R. K., Kushwaha, S. R., Singh, T. P. (2006): Protective role of antioxidant enzymes under high temperature stress. - Plant Science An International Journal of Experimental Plant Biology 171: 382-388.

[2] Blokhina, O. (2003): Antioxidants, oxidative damage and oxygen deprivation stress: a review. - Annals of Botany 91: 179-194.

[3] El-Shintinawy, F. (2000): Structural and functional damage caused by boron deficiency in sunflower leaves. - Photosynthetica 36: 565-573.

[4] Ghaley, B. B., Wosten, H., Olesen, J. E., Schelde, K., Baby, S., Karki, Y. K., Borgesen, C. D., Smith, P., Yeluripati, J., Ferrise, R., Bindi, M., Kuikman, P., Lesschen, J. P., Porter, J. R. (2018): Simulation of soil organic carbon effects on long-term winter wheat (Triticum aestivum) production under varying fertilizer inputs. - Front Plant Sci 9: 1158.

[5] Jiang, J., Xing, F., Zeng, X., Zou, Q. (2018): RicyerDB: a database for collecting rice yield-related genes with biological analysis. - Int J Biol Sci 14: 965-970.

[6] Kong, L., Ashraf, U., Cheng, S., Rao, G., Mo, Z., Tian, H., Pan, S., Tang, X. (2017): Short-term water management at early filling stage improves early-season rice 
performance under high temperature stress in South China. - European Journal of Agronomy 90: 117-126.

[7] Li, M., Ashraf, U., Tian, H., Mo, Z., Pan, S., Anjum, S. A., Duan, M., Tang, X. (2016): Manganese-induced regulations in growth, yield formation, quality characters, rice aroma and enzyme involved in 2-acetyl-1-pyrroline biosynthesis in fragrant rice. - Plant Physiology and Biochemistry 103: 167-175.

[8] Liu, T., Huang, J., Chai, K., Cao, C., Li, C. (2018): Effects of N fertilizer sources and tillage practices on $\mathrm{NH} 3$ volatilization, grain yield, and $\mathrm{N}$ use efficiency of rice fields in Central China. - Front Plant Sci 9: 385.

[9] Mahajan, G., Sekhon, N. K., Singh, N., Kaur, R., Sidhu, A. S. (2010): Yield and nitrogenuse efficiency of aromatic rice cultivars in response to nitrogen fertilizer. - Journal of New Seeds 11: 356-368.

[10] Mo, Z., Lei, S., Ashraf, U., Khan, I., Li, Y., Pan, S., Duan, M., Tian, H., Tang, X. (2017): Silicon fertilization modulates 2-acetyl-1-pyrroline content, yield formation and grain quality of aromatic rice. - Journal of Cereal Science 75: 17-24.

[11] Pan, S., Rasul, F., Li, W., Tian, H., Mo, Z., Duan, M., Tang, X. (2013): Roles of plant growth regulators on yield, grain qualities and antioxidant enzyme activities in super hybrid rice (Oryza sativa L.). - Rice (N Y) 6: 9.

[12] Pan, S., Wen, X., Wang, Z., Ashraf, U., Tian, H., Duan, M., Mo, Z., Fan, P., Tang, X. (2017): Benefits of mechanized deep placement of nitrogen fertilizer in direct-seeded rice in South China. - Field Crops Research 203: 139-149.

[13] Peng, S., Buresh, R. J., Huang, J., Zhong, X., Zou, Y., Yang, J., Wang, G., Liu, Y., Hu, R., Tang, Q. (2010): Improving nitrogen fertilization in rice by site-specific $N$ management. A review. - Agronomy for Sustainable Development 30: 649-656.

[14] Ren, Y., Ashraf, U., He, L. X., Mo, Z. W., Wang, F., Wan, X. C., Kong, H., Ran, X. L., Tang, X. R. (2017): Irrigation and nitrogen management practices affect grain yield and 2-acetyl-1-pyrroline content in aromatic rice. - Applied Ecology \& Environmental Research 15: 1447-1460.

[15] Schmalzer, S. (2017): Yuan Longping, hybrid rice, and the meaning of science in the cultural revolution and beyond. - Endeavour 41: 94-101.

[16] Shakoor, A., Xu, Y., Wang, Q., Chen, N., He, F., Zuo, H., Yin, H., Yan, X., Ma, Y., Yang, S. (2018): Effects of fertilizer application schemes and soil environmental factors on nitrous oxide emission fluxes in a rice-wheat cropping system, east China. - PLoS One 13: e0202016.

[17] Sikdar, M. S. I., Rahman, M. M., Islam, M. S., Yeasmin, M. S., Akhter, M. M. (2008): Effect of nitrogen level on aromatic rice varieties and soil fertility status. - International Journal of Sustainable Crop Production.

[18] Sun, L., Xue, Y., Peng, C., Xu, C., Shi, J. (2018): Does sulfur fertilizer influence Cu migration and transformation in colloids of soil pore water from the rice (Oryza sativa L.) rhizosphere? - Environ Pollut 243: 1119-1125.

[19] Wang, L., Zhang, Q. (2017): Boosting rice yield by fine-tuning SPL gene expression. Trends Plant Sci 22: 643-646.

[20] Wu, H., Xiang, J., Zhang, Y., Zhang, Y., Peng, S., Chen, H., Zhu, D. (2018): Effects of post-anthesis nitrogen uptake and translocation on photosynthetic production and rice yield. - Sci Rep 8: 12891.

[21] Zhang, Q. L., Wei, Y. X., Peng, C. L. (2018): Effects of endogenous ascorbic acid on resistance to high-temperature stress in excised rice leaves. - Photosynthetica 56: 14531458.

[22] Zhong, N., Zu, H. (1997): Effect of excess fertilizer phosphorus on some chemical properties of paddy soil derived from red soil and its relation to rice growth. - Pedosphere 7: 59-64. 